\title{
Contribuição ao conhecimento de Couma macrocarpa Barb. Rodr. e C. utilis (Mart.) M. Arg. (Apocynaceae) da Amazônia
}

\author{
Byron W. P. DE Albuquerque(*) \\ Instituto Nacional de Pesquisas \\ da Amazônia
}

\section{SINOPSE}

Informaçōes gerais e anátomo-foliares sobre 2 Couma sāo apresentados neste trabalho, acompanhadas de 4 figuras.

\section{INTRODUÇÃo}

As espécies analisadas neste trabalho são conhecidas pelos nomes vulgares de "sorva grande" (Couma macrocarpa) e "sorva pequena" (Couma utilis).

A importância das Couma na composição floristica da Hiléia é ressaltada por Fróes (1959) e Heinsdijk \& Bastos (1963).

Corrêa (1931), LeCointe (1947), Record \& Hess (1949), Uphof (1959), Mainieri (1962), Heinsdijk \& Bastos (1963), Loureiro \& Silva (1968) e Cavalcante (1972), salientam o valor econômico das madeiras, frutos e látex das Couma.

\section{MATERIAL E MÉTODOS}

Material analisado

\section{Couma macrocarpa}

1 -Coletor: W. Rodrigues; $n .^{\circ}$ de herbário: INPA 2973; lacal de coleta: cachoeira baixa do Tarumã, Manaus, Amazonas, em 25-11-1955; determinador: W. Rodrigues .

2 - Coletores: Byron, Luiz Coelho, $459 ; n .^{\circ}$ de herbário: INPA 35176; local de coleta: Reserva Florestal Ducke, Manaus, Amazonas, em 29-7-1971; determinador: Byron de Albuquerque.

\section{Couma utilis}

1 - Coletores: G. T. Prance, B. S. Pena e J. F. Ramos, $3293 ; n .^{\circ}$ de herbário: INPA 18869; local de coleta: entre Ipixuna e Itaparaná, km 60 da estrada HumaitáLábrea, rio Madeira, Município de Humaitá, Amazonas, em 25-11-1966; determinador: M. Markgraf.

2 - Coletores: Byron, Luiz Coelho, $369 ; n .^{\circ}$ de herbário: INPA 28404; local de coleta: Ponta Negra, Manaus, Amazonas, em 28-1-1971; determinador: Byron de Albuquerque.

\section{Metodologia}

As folhas utilizadas para as observações eram perfeitamente adultas.

Todo o material usado foi previamente fixado em FAA (Sass, 1951).

Os cortes histológicos foram feitos a mão livre e clarificados em solução aquosa de hipoclorito de sódio a $50 \%$. Para a identificaçăo da lignina foi empregado ensaio com floroglucina e ácido a $50 \%$ (Johansen, 1940).

A epiderme foi dissociada com o uso da mistura de Jeffrey, ácido crômico a $10 \%$ e ácido nítrico a $10 \%$, em partes iguais (Johansen, 1940). Para a contagem de estomas por $\mathrm{mm}^{2}$ foram utilizados fragmentos das regiôes proximal, mediana e distal da lâmina foliar, incluindo margem e com o auxílio de câmara clara foi desenhado um quadrado de $200 \mu$ de lado.

Para o exame da nervação foliar, folhas foram diafanizadas em solução aquosa de $\mathrm{Hi}$ -

(") Bolsista do Conselho Nacional de Pesquisas. 
dróxido de sódio a $5 \%$, coradas com azul de anilina (sol. aquosa a $1 \%$ ) e montadas em xarope de "Apathy".

Todos os desenhos foram feitos por meio de câmara clara e ampliador fotográfico para negativo.

\section{Resultados}

A - INFORMAÇÕES GERAIS SOBRE AS ESPÉCIES

Couma macrocarpa Barb. Rodr. (1891); Ducke (1922); Lemée (1953).

Nomes comuns: "Sorva grande" (Manaus; Óbidos); "Sorva da mata" (Manaus); "Cunã-Açu" (Parintins); "Sorva" (Planalto Amazônico, entre os rios Tapajós e Tocantins); "Leche caspi", "Cumã-açu" (Peru).

Hábito: árvore de $8-22 \mathrm{~m}$ de altura, $12.30 \mathrm{~cm}$ de diâmetro (DAP; DBH), da mata primária de terra firme, argilosa ou silicosa. dos arredores de Manaus (comum), às vezes em capoeiras fechadas ou abertas, silicosas, raramente terrenos úmidos (Lou. reiro \& Silva, 1968); casca muito rugosa, bastante espersa, com látex branco, abundante, saboroso.

Folhas: grandes, em verticilos ternados ou quaternados, largo-elípticas ou ovadas, de base cordiforme ou obtuso-arredondada e ápice obtuso-acuminado, cartáceas, moles; nervuras secundárias numerosas.

Inflorescência: axilar, nos extremos dos ramos, multiflora, corimbiforme.

Flores: róseas, passando a roxas, aromáticas.

Fruto: baga arredondada, com polpa doce, comestivel; sementes elipsóides, achatadas.

Fenologia: Floresce de junho a setembro e a frutificação ocorre de novembro a março do ano seguinte.

Distribuição geográfica: Amazonas (Manaus); Barcelos e Cucuí (rio Negro); Pará (Faro, Obidos, campos do Ariramba (rio Trombetas), foz do rio Tapajós, Juriti VeIho, Bela Vista); Território Federal de Rondônia; Amazônia peruana; Colômbia.
Couma utilis (Mart.) M. Arg. (Müller, 1860; Ducke, 1922).

Nomes comuns: "Sorva pequena", "Sorva miúda", "Sorvinha" (Manaus); "Sorva" (Manaus; Cucuí; Pará); "Soruvina" (estrada Humaitá-Lábrea).

Hábito: árvore de $4-20 \mathrm{~m}$ de altura, das campinas (solo silicoso), campos (solo argiloso ou silicoso) ou matas secundárias (solo silicoso ou argilo-silicoso), raro em matas primárias; casca espessa, rugosa, com abundante látex branco, doce, potável. Também cultivada.

Folhas: ternado-verticiladas, oblongo-obovadas ou elípticas, de base aguda ou às vezes subobtusa e de ápice curtamente acuminado, às vezes obtuso, cartáceas, porém firmes.

Inflorescência: axilar, disposta nas extremidades dos ramos, corimbiforme, multiflora.

Flores: róseas.

Fruto: bagas globosas, menores que na espécie anterior, comestíveis, saborosas.

Fenologia: Floresce de maio a janeiro do ano posterior e a maturação dos frutos de agosto a março do ano seguinte.

Área de distribuição: Amazonas (espontânea); Manaus (comum nos arredores); alto rio Negro; Cucuí; rio Solimões; Coari; Borba; estrada Humaitá-Lábrea; Pará (Mis são Cururu (alto Tapajós); Mariapixi, entre Faro e Óbidos).

\section{$B$ - Dados ANATÔMicos das FolHas}

As folhas das duas espécies apresentam estrutura dorsiventral (bifacial).

\section{Couma macrocarpa}

\section{NERVAÇÃO FOLIAR}

Padrão: Camptódromo("), a partir da base do limbo até a nona ou décima nervura secundária, e daí para o ápice broquidódromo (Fig. 1, B). Rede de nervuras reticulada; nervuras secundárias numerosas $e$ terciárias laterais abundantes; nervuras pseudo-secundárias bem destacadas; rede de nervuras superior as terciárias relativamente esparsa, com elementos terminais helicoidais, livres (Fig. 1, D e F). 

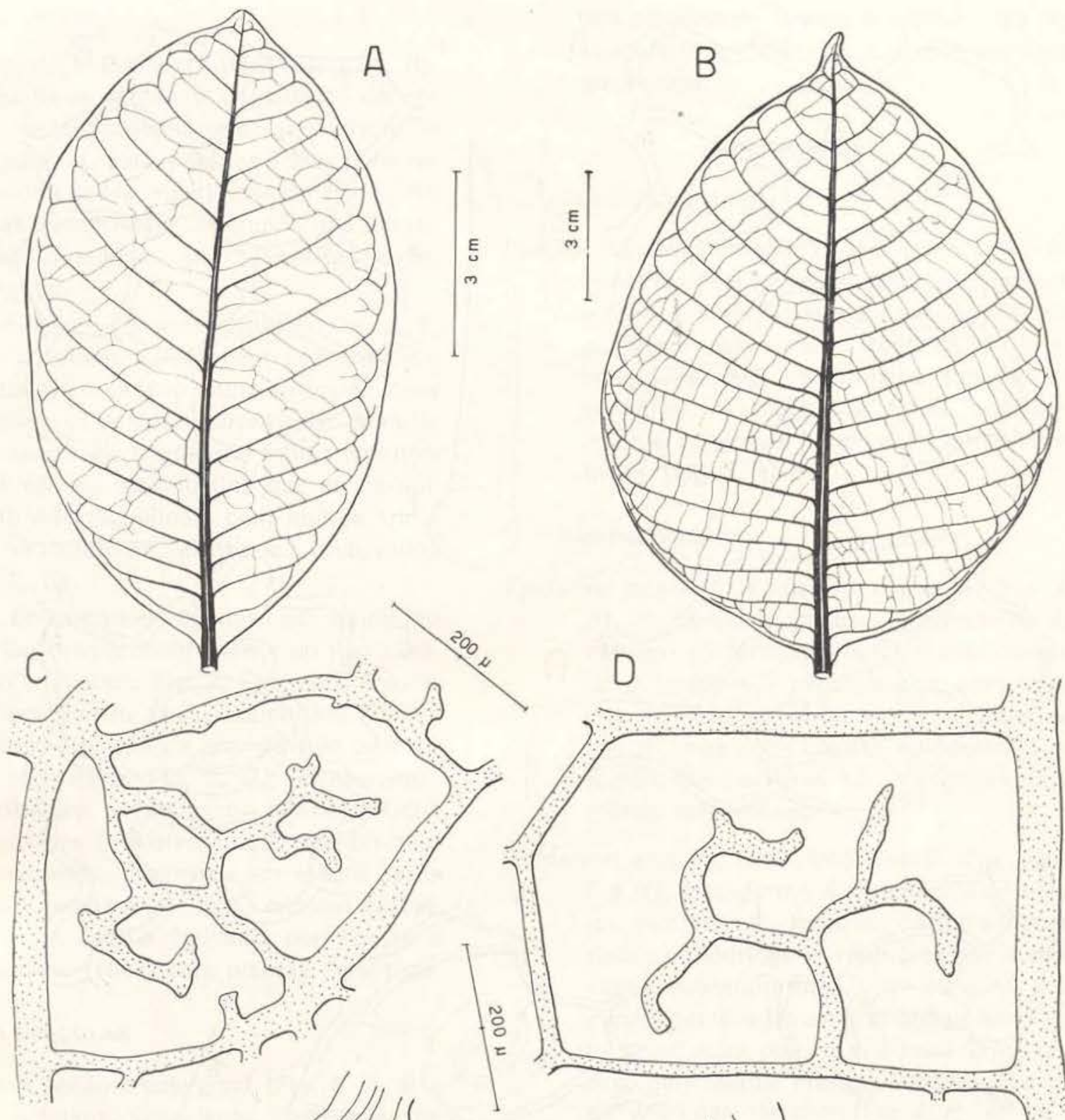

D
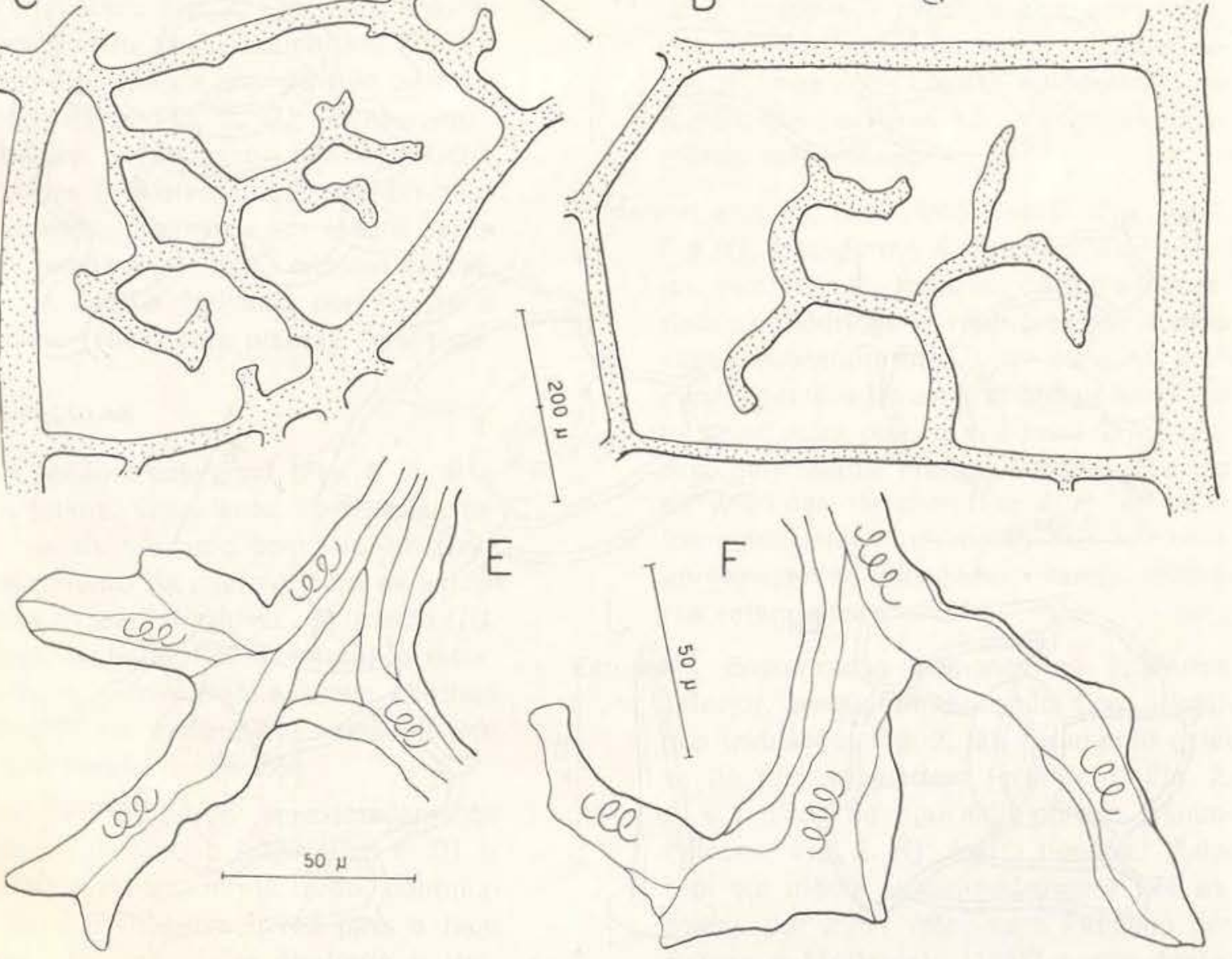

$E$

Fig. 1 - Aspecto geral da nervação: A - Couma utilis; B - C. macrocarpa. Detalhe da rede de nervuras: $\mathrm{C}-C$. utilis; D $-C$. macrocarpa Detalhe dos elementos terminais : E - Couma utilis; $\mathrm{F}-\mathrm{C}$. macrocarpa (Desenhis de J. Dellome). 

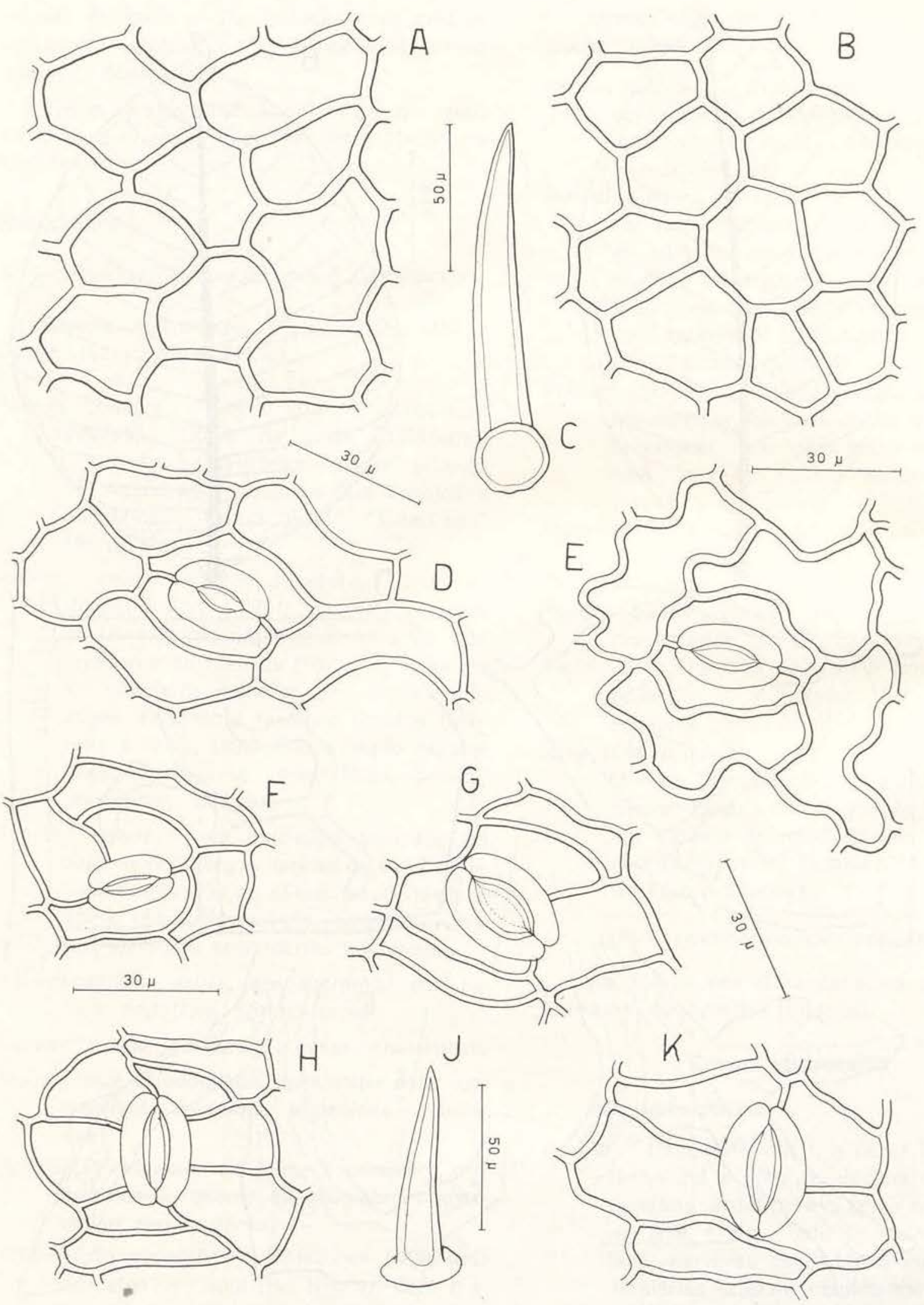

Fig. 2 - Epiderme adaxial: A - Couma utilis; B - C. macrocarpa. Tricoma unicelular.: C Couma macrocarpa; $\mathrm{J}-C$. utilis. Epiderme abaxial: D, F e $\mathrm{H}-$ Couma utilis; $\mathrm{E}, \mathrm{G}$ e $\mathrm{K}-C$. macrocarpa (Desenhos de J. Dellome). 


\section{LÂMINA FOLIAR}

Epiderme adaxial: Em vista frontal (Fig. 2, B), apresenta-se glabra e constituída de células heterodimensionais, poliédricas a triangulares, com paredes radiais de retas a onduladas, relativamente finas. As células epidérmicas na região das nervuras são alongadas, com várias em forma retangular.

Epiderme abaxial: Em vista frontal (Fig. 2, E, $G$ e $K$ ), células epidérmicas heterodimensionais, de contorno muito irregular, com paredes anticlinais fortemente onduladas, finas. As células na região das nervuras são do mesmo tipo que as da epi derme adaxial; pilosa, com muitos tricomas unicelulares, eretos ou recurvados (Fig. 2, C).

Estomas: Encontrados apenas na epiderme inferior, predominantemente do tipo paracítico (rubiáceo; Fig. 2, E); também existem poucos do tipo anomocitico (ranunculáceo; Fig. 2, K) e raro do tipo anisocitico (crucifero; Fig. 2, G); densamente distribuídos na epiderme abaxial. Células guardas (oclosivas) com espessamentos externos. Ocorrem em média cerca de 336 estomas por $\mathrm{mm}^{2}$, número aproximado da média indicada por Eames e McDaniels (1947) para plantas mesófitas.

\section{REGIÃO VASCULAR}

Peciolo: Em seção transversal (Fig. 4, A, B e $C$ ), os feixes vasculares apresentam-se em forma de um arco contínuo em todo o comprimento do pecíolo, com as extremidades livres, infletidas. O floema ( $\mathrm{fl}$ ). em faixa contínua, limita externa e internamente o xilema (xi); existem cordões de floema no parênquima medular em toda a extensão do pecíolo.

Nervura mediana: A altura aproximadamente da metade da lâmina foliar (Fig. 4, D), o sistema vascular forma arco contínuo com as extremidades livres para a face adaxial. Há uma faixa contínua e irregular de floema externa e internamente limitando o xilema. Na face adaxial exis- tem cordões de floema e xilema. No parênquima medular há somente cordões de floema.

\section{Couma utilis}

\section{NERVAÇÃO FOLIAR}

Padrão: do tipo broquidódromo (Fig. 1, A), às vezes apresenta camptodromia, principalmente nas nervuras secundárias do terço basal do limbo. Rede de nervuras reticulada; rede de nervuras superior às terciárias relativamente densa, com elementos terminais helicoidais, geralmente livres (Fig. 1, $C$ e $E$ ).

\section{LÂMINA FOLIAR}

Epiderme adaxial: Vista frontalmente (Fig. 2, A), apresenta-se glabra. Constitui-se de células epidérmicas heterodimensionais. de poliédricas a retangulares, com paredes radiais recurvadas ou retas, relativamente finas. As células epidérmicas na região das nervuras são alongadas, com muitas retangulares.

Epiderme abaxial: Em vista frontal (Fig. 2, D, $\mathrm{F}$ e $\mathrm{H}$ ), a epiderme é constituída de células de contorno irregular, de tamanho variado, poliédricas a retangulares, muitas vezes subreniformes, com paredes anticlinais retas a levemente onduladas, muito finas; com poucos tricomas unicelulares, geralmente eretos, mais freqüentes ao longo das nervuras (Fig. 2, J). As células epidérmicas na região das nervuras apresentam-se alongadas, sendo inúmeras retangulares.

Estomas: Encontrados somente na epiderme inferior, freqüentemente do tipo paracitico (rubiáceo; Fig. 2, D); raramente existe do tipo anisocítico (crucífero; Fig. 2, F) e poucos do tipo anomocitico (ranunculáceo; Fig. 2, $H$ ); muito densos. Existem em média aproximadamente 504 estomas por $\mathrm{mm}^{2}$, valor este indicado por Eames e McDaniels (1947) como dentro do limite característico de plantas mesófitas.

(*) Nomenclatura definida por Ettingshausen (1861): Felippe e I. Alencastro (1966). 


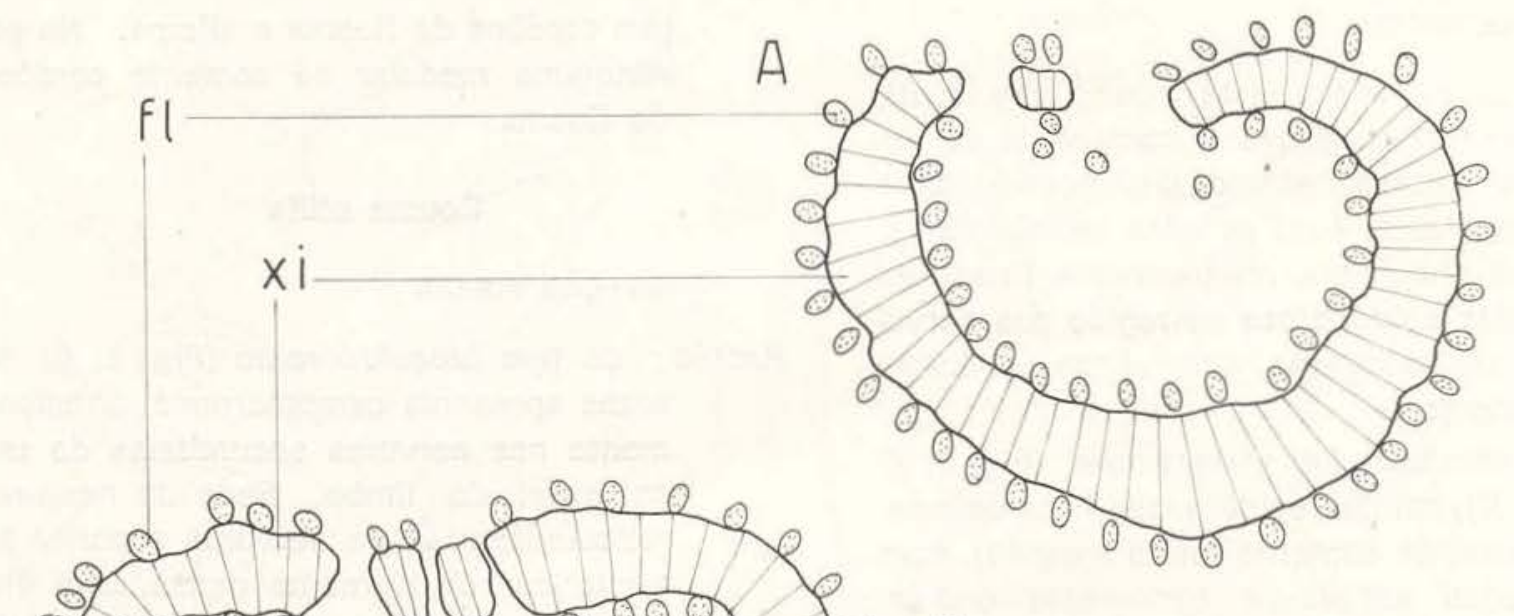

B
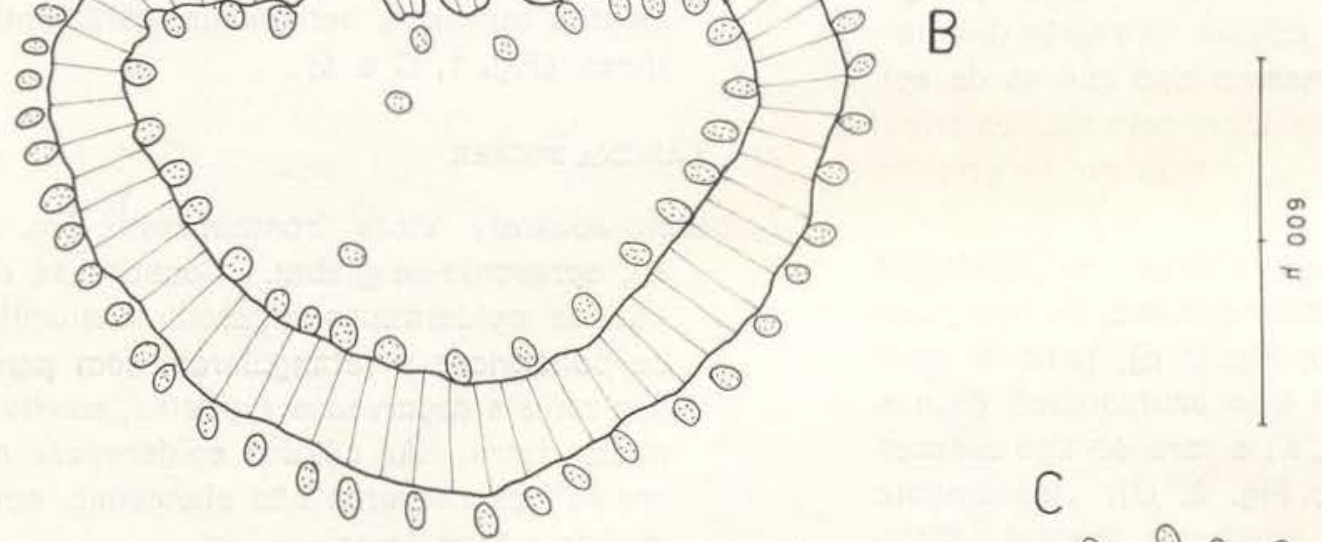

C
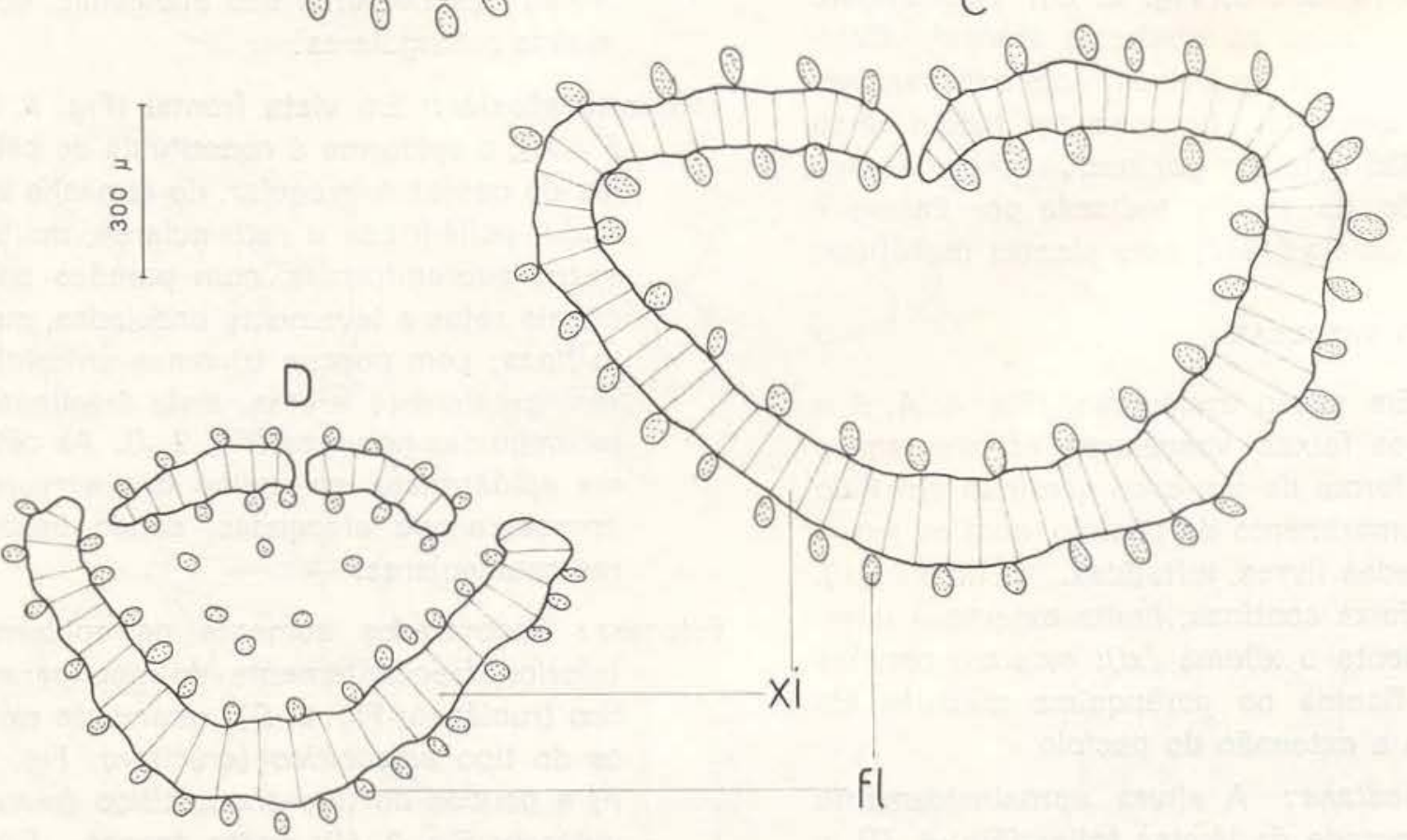

Fig. 3 - Couma utilis: A, B e C - Seçã.) transversal dos elementos vasculares no extremo proximal, na altura aproximadamente do nível médio do comprimento e no extremo distal do pecíolo, respectivamente ( $x i$, xilema; $f l$, floema); D - Seção transversal dos elementos vasculares aproximadamente a altura da metade da extensão da nervura mediana (Desenhos de J. Dellome). 


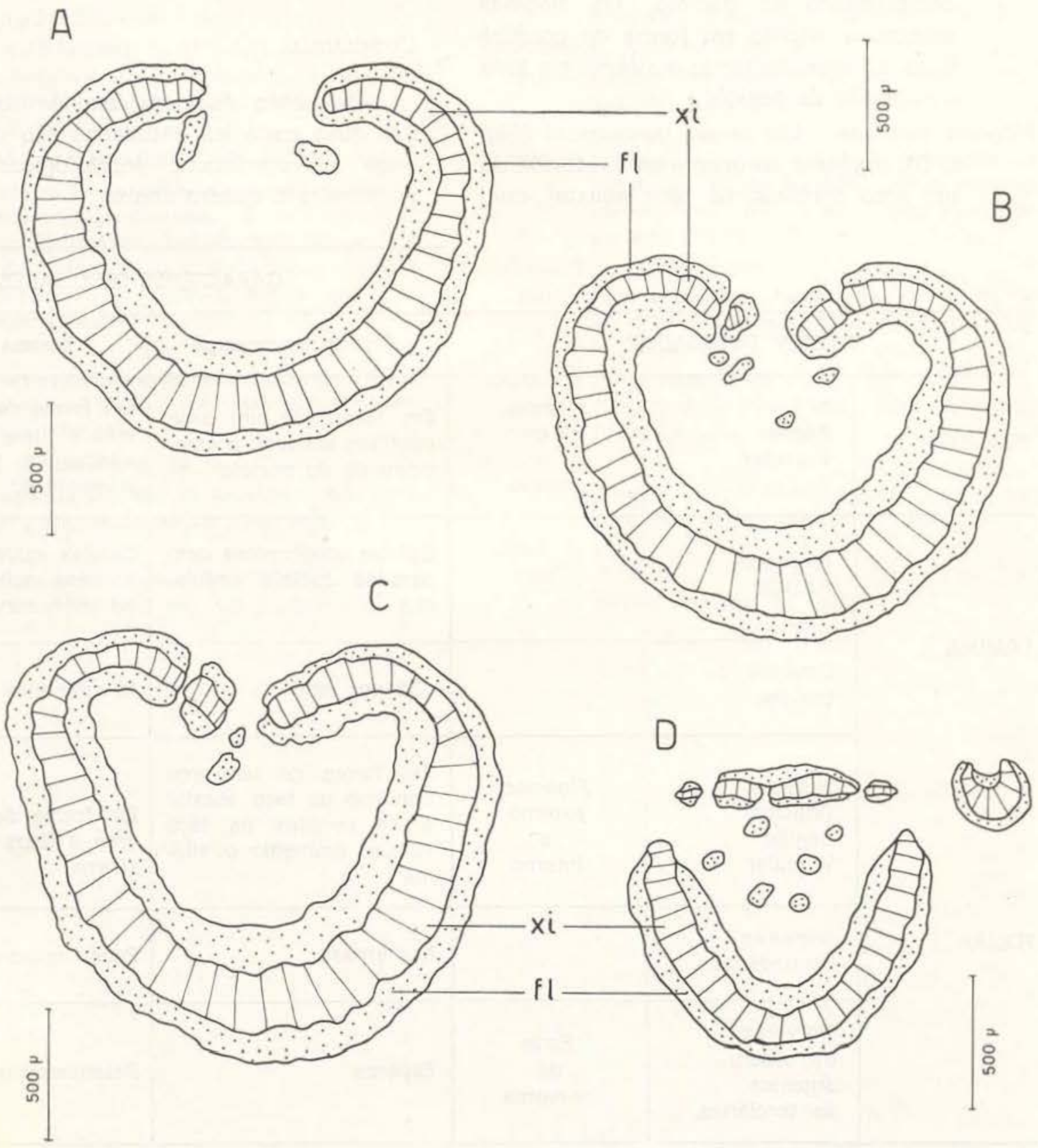

Fig, 4-Couma macrocarpo: A, B, C - Seção transversal dos elementos vasculares no extremo proximal, na altura aproximadamente do nível médio do comprimento e no extremo distal do pecíolo, respectivamente ( $x i$, xilema; $f l$, floema) D - Seção transversal dos elementos vasculares aproximadamente a altura da metade do comprimento da nervura mediana (Desenhos de J. Dellome). 


\section{REGIÃO VASCULAR}

Peciolo: Em seção transversal (Fig. 3, A-C), o xilema apresenta-se em forma de um arco contínuo, com as extremidades livres, ligeiramente infletidas, em todo o comprimento do pecíolo. Os floemas externo e interno em forma de cordões finos e livres limitando o xilema em toda a extensão do pecíolo.

Nervura mediana: Em seção transversal (Fig. $3, D$ ), o xilema apresenta-se em forma de um arco contínuo na face abaxial, com as extremidades livres para a face ada. xial. Há cordões espessos de xilema na face adaxial. O floema forma cordões livres e finos, limitando externa e inter. namente o xilema. Existem cordões de floema no parênquima medular.

\section{CONCLUSÃo}

Do ponto de vista taxonômico, as folhas das duas espécies estudadas são distintas em suas características morfológicas, conforme demonstra o quadro abaixo :

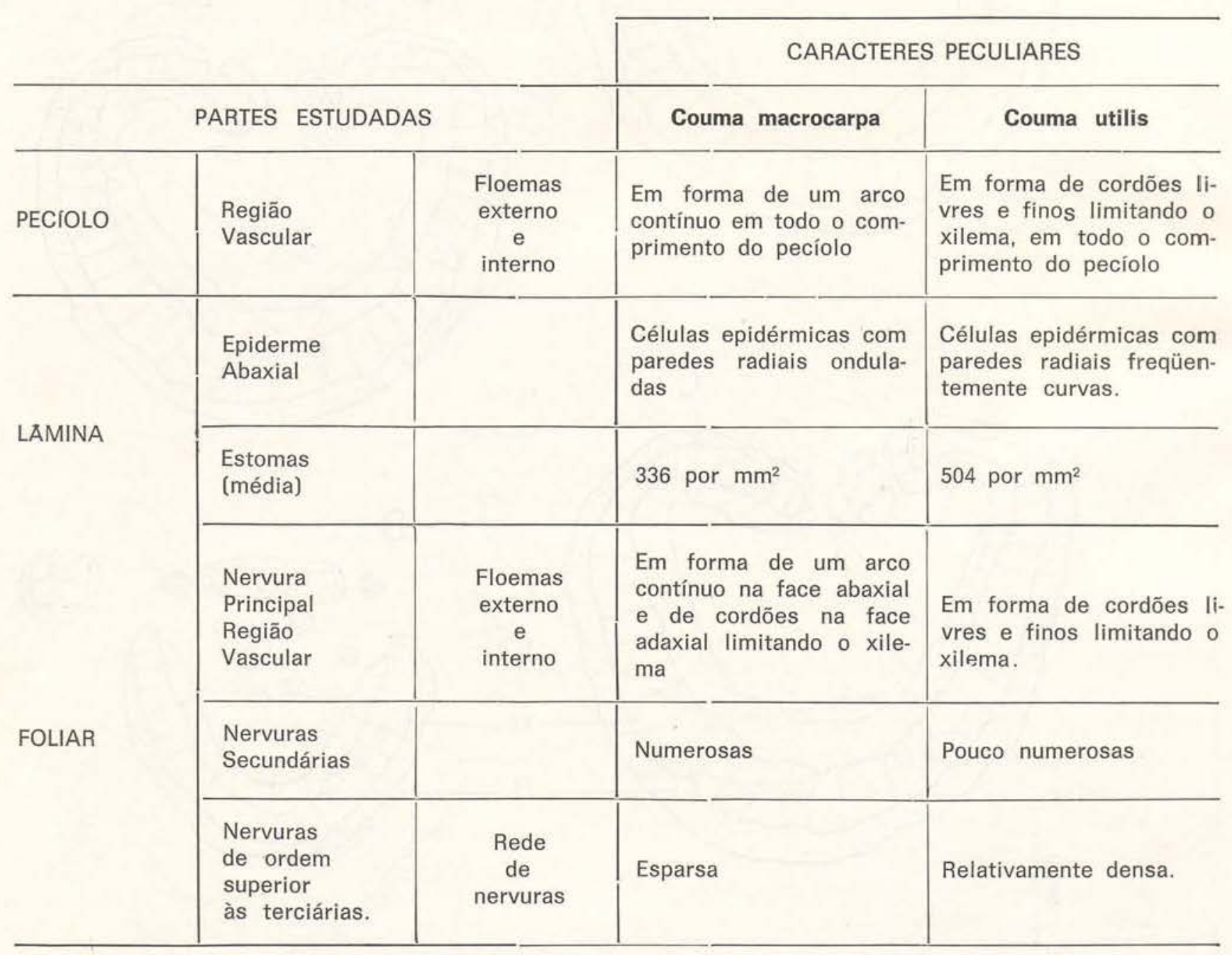

\section{SUMMARY}

The author studies some morphological aspects on two species, of Couma (Apocynaceae) dealing with their taxonomy, and geographic distribution and general botanical data are also considered.

Results indicate that foliar morphology may be used for specific identification. Results are aocumented by descriptions and by drawings.

\section{BIBLIOGRAFIA CITADA}

BARBOSA RODRIgues, J.

1891 - Eclogae plantarum novarum. Vellosia, R. Janeiro, $1: 1-88$, est. $1, \mathrm{~B}$.

Cavalcante, $P$.

1972 - Frutas comestíveis da Amazônia. Pub. Avulsas Mus. Pa. Emílio Goeldi, Belém, 17:1-84 ilust. 
CORREA, M. P.

1931 - Dicionário de plantas úteis do Brasil e das exóticas cultivadas. Rio de Janeiro, Imp. nacional, v. 2, ilust.

DUCKE, $A$.

1922 - Plantas nouvelles ou peu connues de la région amazonienne. II. Arq. Jard. Bot., R. Janeiro, 3:3-281, ilust.

Eames A. J. \& McDaniels, L. H.

1947 - An introduction to plant anatomy. 2. ed. New York and London, McGraw-Hill Book co. p. $81-122$.

Felippe, G. M. \& Alencastro, F. M. de R.

1966 - Contribuição ao estudo da nervação foliar das Compositae dos Cerrados. I. - Tribus Heleniae, Heliantheae, Inuleae, Mutisieae e Senecionae. In: II Simpósio sobre o Cerrado Anais Acad. Bras, Cienc., Rio de Janeiru, 38 (suplemento) :125-157, ilust.

Fróes, R. L.

1959 - Informações sobre algumas plantas do Planalto Amazônico. Bol. Técn. Inst. Agron. Norte, Belém, 35:3-113.

HeinskiJK, D. \& Bastos, A. De $\mathbf{M}$.

1963 - Inventários florestais na Amazônia. Bol. Serv. Flor, , Rio de Janeiro, 6:1-100, ilust.

JOHANSEN, A. D.

1940 - Plant microtechnique. New York and London, McGraw-Hill book co., 523 p., ilust.
Le CoInte, Paul

1947 - Amazônia brasileira III. Arvores e plantas úteis (indigenas $e$ aclimatadas). 2. ed. São Paulo, Ed. Nacional. 506p. ilust. (Brasiliana. 251).

Lemée, A.

1953 - Dilleniacées à Composées. Flore de la Guyana Française. Paris, Paul LeChevalier. v. 3

Loureiro, A. A. \& SIllva, M. F.

1968 - Catálogo das madeiras da Amazônia. Belém, SUDAM. v. 1, p. 63-68.

MAINIERI, C.

1962 - Madeiras leves da Amazônia empregadas em caixotaria. Estudo Anatômico macro e microscópico. Pub. Inst. Pesq. Tecn., São Paulo 686:6-7.

MÜLLER, J

1860 - "Apocynaceae". In: Martius, C. F. Ph. de - Flora Brasiliensis. Leipzig. 6(1):1-196, est. 1-54.

RECORD, S. J. \& Hess, R. W.

1949 - Timbers of the New World. New Haven, Yale University press. 640p.

Sıss, J. E.

1951 - Botanical microtechnique. 2nd ed. Ames, Iowa State College press. p. 99-109.

Urнof, J. C.

1959 - Dictionary of Economic plants. New York, Hafner publishing co. $400 \mathrm{p}$. 